\title{
microRNA-22 downregulation of galectin-9 influences lymphocyte apoptosis and tumor cell proliferation in liver cancer
}

\author{
QIANQIAN YANG*, WEICHAO JIANG ${ }^{*}$, CHUNBO ZHUANG, ZHI GENG, \\ CHEN HOU, DA HUANG, LIHUA HU and XIAOBEI WANG \\ Department of Clinical Laboratory, Union Hospital, Tongji Medical College, \\ Huazhong University of Science and Technology, Wuhan, Hubei 430022, P.R. China
}

Received May 6, 2015; Accepted June 15, 2015

DOI: 10.3892/or.2015.4167

\begin{abstract}
Galectin-9 (Gal-9) plays an important role in both the immune response and tumor progression, while microRNAs act as tumor regulators to mediate tumorigenesis. However, the underlying molecular mechanisms remain unknown. In the present study, we investigated the relationship between Gal-9 and microRNA-mediated regulation in liver cancer. We examined Gal-9 expression using qRT-PCR and western blot analysis and found that it was markedly upregulated in human liver cancer cells compared with the level in normal hepatocytes. We co-cultured peripheral blood mononuclear cells (PBMCs) and tumor cells and observed that Gal-9 induced lymphocyte apoptosis and tumor cell immune escape using flow cytometric analysis and WST-1 assay. We found that miR-22 was downregulated in liver cancer tissues and cell lines and confirmed that miR-22 directly targeted the Gal-9 3'UTR and negatively regulated Gal-9 expression by luciferase reporter assay and transfection of microRNA mimics. We also observed that the Gal-9/miR-22 axis may influence lymphocyte apoptosis and tumor cell proliferation. These studies contribute to a further understanding of the microRNA-mediated regulation of the Gal-9 pathway and elucidate novel therapeutic targets for liver cancer.
\end{abstract}

\section{Introduction}

Liver cancer is one of the most prevalent malignant tumors, and is the third leading cause of cancer-related mortality

Correspondence to: Professor Lihua Hu or Dr Xiaobei Wang, Department of Clinical Laboratory, Union Hospital, Tongji Medical College, Huazhong University of Science and Technology, 1277 Jiefang Road, Wuhan, Hubei 430022, P.R. China

E-mail: lihuahu@hust.edu.cn

E-mail: windflower6174@gmail.com

${ }^{*}$ Contributed equally

Key words: galectin-9, microRNA, miR-22, Tim-3, liver cancer worldwide, especially in parts of Asia and Africa (1). There are $\sim 750,000$ new cases of liver cancer, in which $85-90 \%$ are hepatocellular carcinoma (HCC), reported globally per year (2). Current standard practices for the treatment of liver cancer, surgical resection and liver transplantation, are less than satisfactory due to intra- and extra-hepatic metastasis and post-surgical recurrence $(3,4)$. Numerous studies have determined the pathogenesis of liver cancer; however, the accurate molecular mechanisms underlying the pathogenesis and progression of liver cancer remain poorly understood.

Galectin-9 (Gal-9), a $\beta$-galactoside-binding lectin with two carbohydrate-recognition domains, was first identified as an eosinophil chemoattractant and activation factor $(5,6)$. An increasing amount of evidence suggests that Gal-9 may modulate a variety of biological functions and play an important role in both immune response and tumor progression $(7,8)$. As one of the specific ligands of T-cell immunoglobulin and mucin domain 3 (Tim-3), a Th1-specific type 1 membrane protein, Gal-9 is an important inhibitory immune molecule (9). Binding of Gal-9 to Tim-3 causes an inhibitory signal that results in the apoptosis of effector cells, negatively regulates Th1-type immunity and induces tumor immune tolerance and immune evasion $(10,11)$. Subsequently, Gal-9 was identified to be ubiquitously expressed in a variety of tumor tissues and cell lines and its expression level was closely related with malignant tumor prognosis (12).

microRNAs (miRNAs) are a class of non-coding single-stranded RNA molecules with 22-24 nucleotides, which bind to the 3'-untranslated region (3'UTR) of target mRNAs by base pairing. miRNAs regulate the expression of target genes through post-transcriptional inhibition or induced degradation (13-15). By inhibiting the protein synthesis of multiple targets, miRNAs play an important role in many cellular pathways $(16,17)$. Moreover, recent evidence shows that miRNAs act as tumor-suppressor genes or oncogenes in human cancers (18). The abnormal expression of miRNAs may affect the development and progression of liver cancer.

However, to the best of our knowledge, no previous study has aimed to determine the mechanism of Gal-9 and miRNAs involved in liver cancer. We hypothesized that there might be miRNAs that regulate the expression of Gal-9 and affect 
the Tim3/Gal-9 pathway influencing the immune response and tumor progression in liver cancer. In the present study, we found that 4 miRNAs (miR-22, 296-3p, 455-5p and 491-5p) were potential regulators of Gal-9 and confirmed that miR-22 may directly inhibit Gal-9 expression and cause lymphocyte apoptosis and tumor cell proliferation. Our results suggest that miR-22 has potential therapeutic value for the treatment of liver cancer.

\section{Materials and methods}

Tissue collection. Primary human liver cancer tissue and corresponding adjacent tissue $(<2 \mathrm{~cm}$ away from the tumor area) samples were obtained from 10 patients who underwent primary surgical resection of liver cancer at the Department of Hepatobiliary Surgery, Union Hospital, Tongji Medical College, Huazhong University of Science and Technology. All participants provided written informed consent, and the study protocols were approved by the hospital ethics committee. Medical records of the patients, including age and gender, tumor staging, pathological diagnosis and surgical records were collected. The tissues were immediately snap-frozen in liquid nitrogen and stored at $-80^{\circ} \mathrm{C}$ until total RNA was extracted.

Cell culture. Normal hepatocyte cell line Lo2 and human hepatocellular carcinoma cell lines HepG2 and SMMC7721 were purchased from the Chinese Institute of Biochemistry and Cell Biology and cultured in RPMI-1640 medium (Hyclone, Logan, Utah, USA) containing 10\% fetal bovine serum (FBS) (Gibco, Grand Island, NY, USA), $1 \mathrm{U} / \mathrm{ml}$ penicillin and $1 \mu \mathrm{g} / \mathrm{ml}$ streptomycin (Gibco). Cells were grown in a humidified atmosphere of $5 \%$ carbon dioxide at $37^{\circ} \mathrm{C}$. All cell lines were authenticated and characterized by the cell bank. The cells were expanded immediately and multiple aliquots were cryopreserved. Cells were used within 6 months of resuscitation

Quantitative real-time PCR ( $q R T-P C R)$. Total RNA and small RNA were extracted from the cell lines and tissues using TRIzol ${ }^{\circledR}$ reagent (Invitrogen, Carlsbad, CA, USA). The purity and integrity of the RNA sample were assessed using a NanoDrop 2000 UV-Vis Spectrophotometer (Thermo Scientific, Waltham, MA, USA), and $500 \mathrm{ng}$ RNA was transcribed into cDNA using the PrimeScript ${ }^{\mathrm{TM}}$ RT reagent kit (Takara, Dalian, China) according to the manufacturer's instructions. The obtained cDNA was used as a template to perform PCR amplification using the SYBR ${ }^{\circledR}$ Premix Ex Taq $^{\text {TM }}$ II kit (Takara). Human Gal-9, GAPDH, miRNAs and U6 mRNA levels were analyzed using qRT-PCR with the Mx3000P system (Agilent Technologies, Santa Clara, CA, USA). GAPDH was used as an internal control for Gal-9 detection and U6 for miRNA detection. Each $20 \mu \mathrm{l}$ reaction system consisted of $2 \mu \mathrm{l}$ of cDNA, $10 \mu \mathrm{l} \mathrm{SYBR}{ }^{\circledR}$ Premix Ex Taq ${ }^{\mathrm{TM}}$ II, $10 \mu \mathrm{mol} / 1$ of both sense and antisense primers. All PCR reactions were carried out as follows: initial denaturation at $95^{\circ} \mathrm{C}$ for $30 \mathrm{sec}$, followed by 40 cycles of denaturation at $95^{\circ} \mathrm{C}$ for $5 \mathrm{sec}$, annealing at $60^{\circ} \mathrm{C}$ for $30 \mathrm{sec}$ and extension at $72^{\circ} \mathrm{C}$ for $30 \mathrm{sec}$. Each experiment contained at least three replicates, and the results were calculated according to the method $2^{-\Delta \Delta \mathrm{CT}}$.
The PCR primers used in this study are available upon request and are listed in Table I.

Western blot analysis. Protein was extracted from the cells using RIPA lysis buffer containing EDTA-free Complete Protease Inhibitors (Roche, Mannheim, Germany). After the protein concentration was measured, it was mixed with SDS loading buffer, separated by $10 \%$ SDS-PAGE and transferred onto nitrocellulose membranes. To block nonspecific binding, the membranes were incubated at room temperature for $1 \mathrm{~h}$ with $5 \%$ skim milk powder, followed by an overnight incubation at $4^{\circ} \mathrm{C}$ with the primary antibodies anti-Gal-9 (ImmunoWay Biotechnology Company, Newark, DE, USA) or anti- $\beta$-actin (Cell Signaling Technology, Boston, MA, USA) and the blots were incubated with horseradish peroxidase-labeled secondary antibodies (Cell Signaling Technology). Signals were visualized by ECL chemiluminescence. Changes in protein expression were quantified using ImageJ software (National Institutes of Health, Bethesda, MD, USA). Equal protein loading was assessed by expression of $\beta$-actin.

Target prediction. Bioinformatic analysis was carried out using specific programs: miRanda (http://www.microrna.org) and TargetScan (http:// www.targetscan.org/).

Plasmid construction, miRNA synthesis and transfection. The full-length Gal-9 3'UTR containing a putative miR-22 binding site was amplified by PCR from genomic DNA and cloned at the EcoRI and HindIII sites into the pCMV vector. The specific primers for the wild-type Gal-9 3'UTR vector were as follows: 5'-ATAGAATTCGCGGCTTCCTGGCCCTG-3' and 5'-CGCAAGCTTTGAATGTGCCAACAAGCA-3'. The specific primers for the mutant-type Gal-9 3'UTR vector were as follows: 5'-ATAGAATTCGCGGCTTCCTGGCGGAC-3' and 5'-CGCAAGCTTTGAATGTGCCAACAGCGC-3'. Wild-type and mutant-type inserts were confirmed by sequencing. For the expression of Gal-9, the genomic fragment of Homo sapiens Gal-9 precursor was amplified by PCR using the primer pairs: 5'-GGAGAATTCGAGATGGCCTTCAGC GGTTCCCAG-3 and 5'-CCACTCGAGCGCCTATGTCTG CACATGGGTCAG-3'. The PCR product was cloned into pcDNA3.1 at the EcoRI and XhoI sites and named the Gal-9/pcDNA3.1 vector. miR-22-mimic, miR-491-mimic and miR-control mimic (negative control) were synthesized by Guangzhou RiboBio Co., Ltd. (Guangzhou, China). Cells were transiently transfected by use of Lipofectamine 2000 transfection reagent (Invitrogen, Carlsbad, CA, USA) for $24 \mathrm{~h}$, according to the manufacturer's protocol.

Luciferase reporter gene assay. HepG2 cells were plated in a 96-well plate and co-transfected with miRNA mimics or control mimics with pCMV-Gal-9 3'UTR-WT or pCMV-Gal-9 3'UTR-MU and PRL-TK (Promega, Beijing, China), using Lipofectamine 2000. Cells were collected $24 \mathrm{~h}$ after transfection and luciferase activity was analyzed using the Dual-Luciferase Reporter Assay System Modulus ${ }^{\mathrm{TM}}$ Single Tube Multimode Reader (Turner BioSystems, Madison, WI, USA). The pRL-TK vector that provided the constitutive expression of Renilla luciferase was co-transfected as an internal control to correct for differences in both transfection and harvest efficiencies. 
Table I. PCR primers used in the present study.

\begin{tabular}{|c|c|}
\hline Genes & Primer sequences ( $5^{\prime}$ to $3^{\prime}$ ) \\
\hline Gal-9 & $\begin{array}{l}\text { F: CGCCCCTGGACAGATGTT } \\
\text { R: GACAGGAGGATGGACTTGGA }\end{array}$ \\
\hline GAPDH & $\begin{array}{l}\text { F: GAAGGTGAAGGTCGGAGTC } \\
\text { R: GAAGATGGTGATGGGATTTC }\end{array}$ \\
\hline $\operatorname{miR}-22$ & $\begin{array}{l}\text { RT: GTCGTATCCAGTGCAGGGTCCGAGGTATTCGCACTGGATACGACACAGTTC } \\
\text { F: GCCGAGGGTTGGGTGGAG }\end{array}$ \\
\hline miR-296-3p & $\begin{array}{l}\text { RT: GTCGTATCCAGTGCAGGGTCCGAGGTATTCGCACTGGATACGACGGAGAGC } \\
\text { F: GCCGAGGGTTGGGTGGAG }\end{array}$ \\
\hline $\operatorname{miR}-455-5 p$ & $\begin{array}{l}\text { RT: GTCGTATCCAGTGCAGGGTCCGAGGTATTCGCACTGGATACGACCGATGTA } \\
\text { F: GCCGTATGTGCCTTTGGACT }\end{array}$ \\
\hline $\operatorname{miR}-491-5 p$ & $\begin{array}{l}\text { RT: GTCGTATCCAGTGCAGGGTCCGAGGTATTCGCACTGGATACGACCCTCATG } \\
\text { F: GCCGAGTGGGGAACCCTT }\end{array}$ \\
\hline \multirow[t]{2}{*}{ U6 } & $\begin{array}{l}\text { RT: AACGCTTCACGAATTTGCGT } \\
\text { F: CTCGCTTCGGCAGCACA } \\
\text { R: AACGCTTCACGAATTTGCGT }\end{array}$ \\
\hline & aR: GTGCAGGGTCCGAGGT \\
\hline
\end{tabular}

${ }^{a} \mathrm{miR}-22, \mathrm{miR}-296-3 \mathrm{p}, \mathrm{miR}-491-5 \mathrm{p}, \mathrm{miR}-455-5 \mathrm{p}$.

Transfections were carried out in duplicates and repeated at least twice in independent experiments.

Isolation of peripheral blood mononuclear cells (PBMCs) and co-culture experiments of PBMCs and liver cancer cells. PBMCs were isolated from the venous blood of healthy blood donors. Aliquots of $3 \mathrm{ml}$ of blood were diluted in $3 \mathrm{ml}$ PBS and layered on $6 \mathrm{ml}$ Lymphocyte Separation Media (MD Pacific, Tianjin, China). After centrifugation at 2,000 rpm for $20 \mathrm{~min}$ at room temperature, the PBMCs were recovered from the interphase and washed twice with serum-free RPMI-1640 medium (Hyclone, Logan, Utah, USA) and centrifuged at $1,000 \mathrm{rpm}$ for $10 \mathrm{~min}$. PBMCs were resuspended in complete culture medium and adjusted to $3 \times 10^{6}$ cells $/ \mathrm{ml}$.

For the co-culture experiments, HepG2 liver cancer cells were washed with PBS, diluted in complete medium and transferred to the wells. Transfections were performed using Lipofectamine 2000. After a 24-h transfection, PBMCs were plated in each well for co-culture. After $48 \mathrm{~h}$, the cancer cells and the PBMCs were separated for further analysis.

Cell proliferation assay. The WST-1 assay was used to evaluate cell proliferation. After a 48 -h co-culture, $10 \mu \mathrm{l} /$ well cell proliferation reagent WST-1 (Roche, Mannheim, Germany) was added and incubated for $2 \mathrm{~h}$. The cells were shaken thoroughly for 1 min on a shaker and the absorbance was measured using an ELX808 Universal Microplate Reader (Bio Tek, Winooski, VT, USA). The wavelength for measuring the absorption of the formazan product was $450 \mathrm{~nm}$. All samples were performed in triplicate.

Flow cytometric analysis of cell apoptosis. A cell apoptosis assay was performed using an Annexin-V-Fluos staining kit (Roche, Mannheim, Germany). After co-culture of the
PBMCs and HepG2 cells for $48 \mathrm{~h}$, PBMCs were collected and centrifuged at $1,000 \mathrm{rpm}$ for $5 \mathrm{~min}$ and washed with PBS twice. The cell pellet was resuspended in $100 \mu \mathrm{l}$ of Annexin-V-Fluos labeling solution (Roche) and incubated $10-15 \mathrm{~min}$ at $15-25^{\circ} \mathrm{C}$. All specimens were assessed on a FACS Calibur flow cytometer (BD, Franklin Lake, NJ, USA), and data were analyzed with FlowJo software.

Statistical analysis. The statistical significance was determined using the Student's t-test. All data are expressed as the mean \pm SD. A P-value $<0.05$ was considered to indicate a statistically significant result. All experiments were repeated more than three times and each experiment consisted of triple wells. One representative experiment was selected to construct diagrams and for data analysis.

\section{Results}

Expression of Gal-9 in the liver cancer cell lines. To identify the expression levels of the Gal-9 mRNA and protein in normal liver and liver cancer cells, we performed qRT-PCR and western blot analysis in Lo2 cells as well as in HepG2 and SMMC7721 cells. The Gal-9 mRNA level in HepG2 cells was $\sim 5.3$-fold higher and the level in the SMMC7721 was 2.4-fold higher than that in the Lo2 cells. Furthermore, the Gal-9 protein level in the HepG2 cells was 2-fold higher than that in the Lo2 cells. The results revealed that Gal-9 was significantly upregulated in the liver cancer cells at the mRNA and protein levels compared to these levels in the normal liver cells ( $\mathrm{p}<0.05$, Fig. 1A and B), particularly in the HepG2 cells.

Identification of candidate miRNAs targeting Gal-9 and investigation of their expression levels in human liver cancer tissues and cell lines. Target prediction programs miRanda 


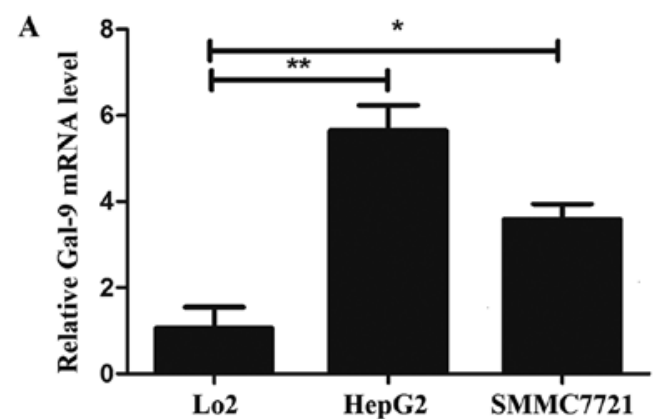

B
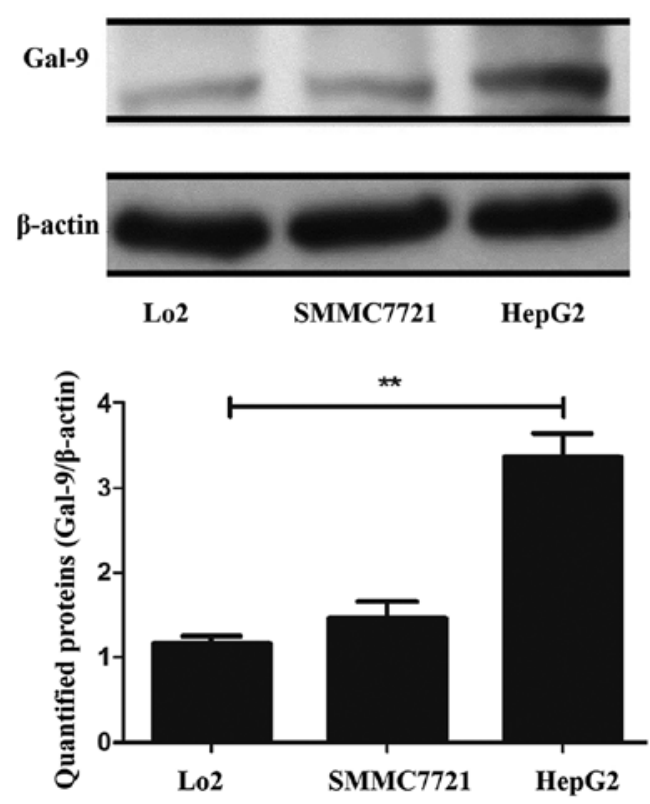

Figure 1. The expression level of Gal-9 in normal liver cells and human liver cancer cell lines. (A) qRT-PCR of Gal-9 mRNA expression level in Lo2, HepG2 and SMMC7721 cells. GAPDH was used as a loading control. ${ }^{* *} \mathrm{P}=0.0038$ and ${ }^{*} \mathrm{P}=0.0136$. (B) Western blot analysis of Gal-9 protein expression level in Lo2, HepG2 and SMMC7721 cells. $\beta$-actin was used as a loading control. ${ }^{* *} \mathrm{P}=0.0016$.

(http://www.microrna.org) and TargetScan (http:// www. targetscan.org/) were used to predict and identify miRNAs that possibly target Gal-9 in liver cancer. The overlapping prediction analysis suggested that 4 miRNAs (miR-22, 296-3p, 455-5p and 491-5p) were potential regulators of Gal-9 (Fig. 2A).

We determined the expression of these 4 miRNAs in normal liver (Lo2) and liver cancer (HepG2) cells. The results showed that miR-22 and miR-491 were significantly downregulated in liver cancer cells than these miRNAs in normal liver cells, particularly miR-22 (Fig. 2B). miR-22 was focused on and its expression level was determined in liver cancer and corresponding adjacent tissues. miR-22 was downregulated in liver cancer tissues compared to that in the corresponding adjacent tissues (Fig. 2C).

Direct inhibition of miR-22 on the expression of Gal-9 via binding to the specific target site in Gal-9 3'UTR. To investigate whether the expression of Gal-9 is regulated by
A

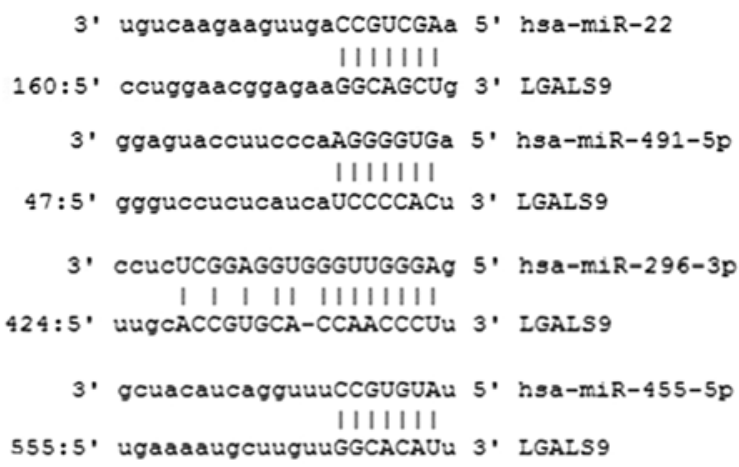

B

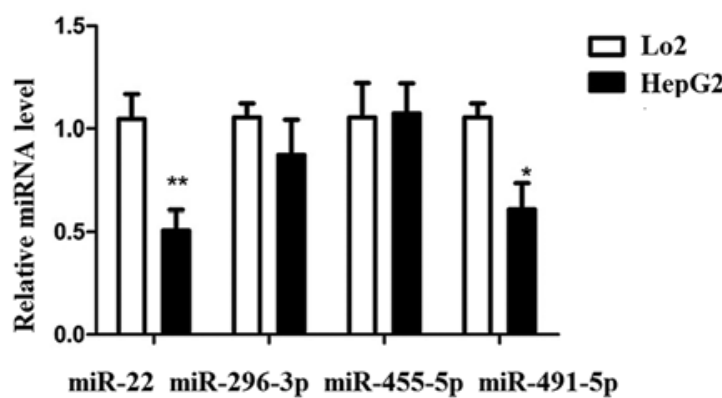

C

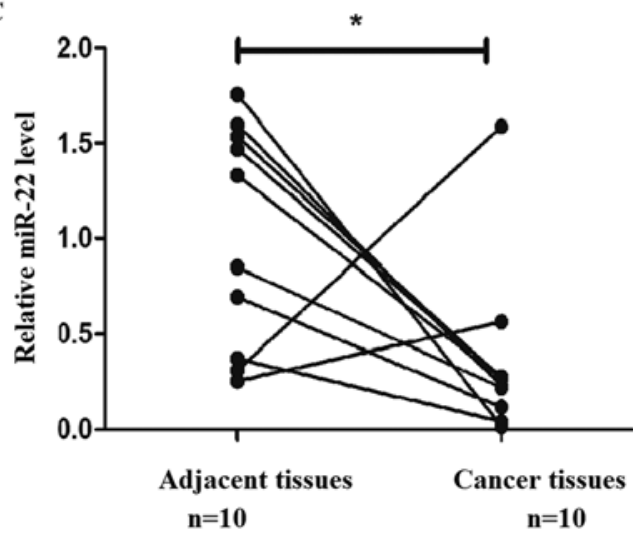

Figure 2. Expression of four candidate miRNAs that target Gal-9. (A) Candidate miRNAs that may modulate Gal-9 expression. LGASL9 is the gene name of galectin-9. (B) Expression of these four miRNAs in HepG2 and Lo2 cells. U6 was used as a loading control. ${ }^{* *} \mathrm{P}=0.0056$ and ${ }^{*} \mathrm{P}=0.0311$. (C) miR-22 expression in tumor and corresponding adjacent tissues. ${ }^{*} \mathrm{P}=0.0462$.

miR-22, the miR-control or miR-22 mimic were transfected into HepG2 cells and the expression levels of Gal-9 mRNA and protein were detected using qRT-PCR and western blot analysis, respectively. We found that the expression of Gal-9 mRNA was slightly decreased, but did not reach a significant level (Fig. 3A). However, the expression of Gal-9 protein was significantly downregulated after transfection of the miR-22 mimics (Fig. 3B) compared with the negative control and miR-control.

To further investigate the mechanisms underlying the regulation of Gal-9 by miR-22, the 3'UTR of Gal-9 was cloned into a reporter vector linking the luciferase open reading frame downstream to generate pCMV-Gal-9-3'UTR wild-type (Gal-9 3'UTR-WT) and pCMV-Gal-9-3'UTR mutant-type (Gal-9 3'UTR-MU). The two plasmids were transfected into HepG2 cells, respectively, together with the miR-control 

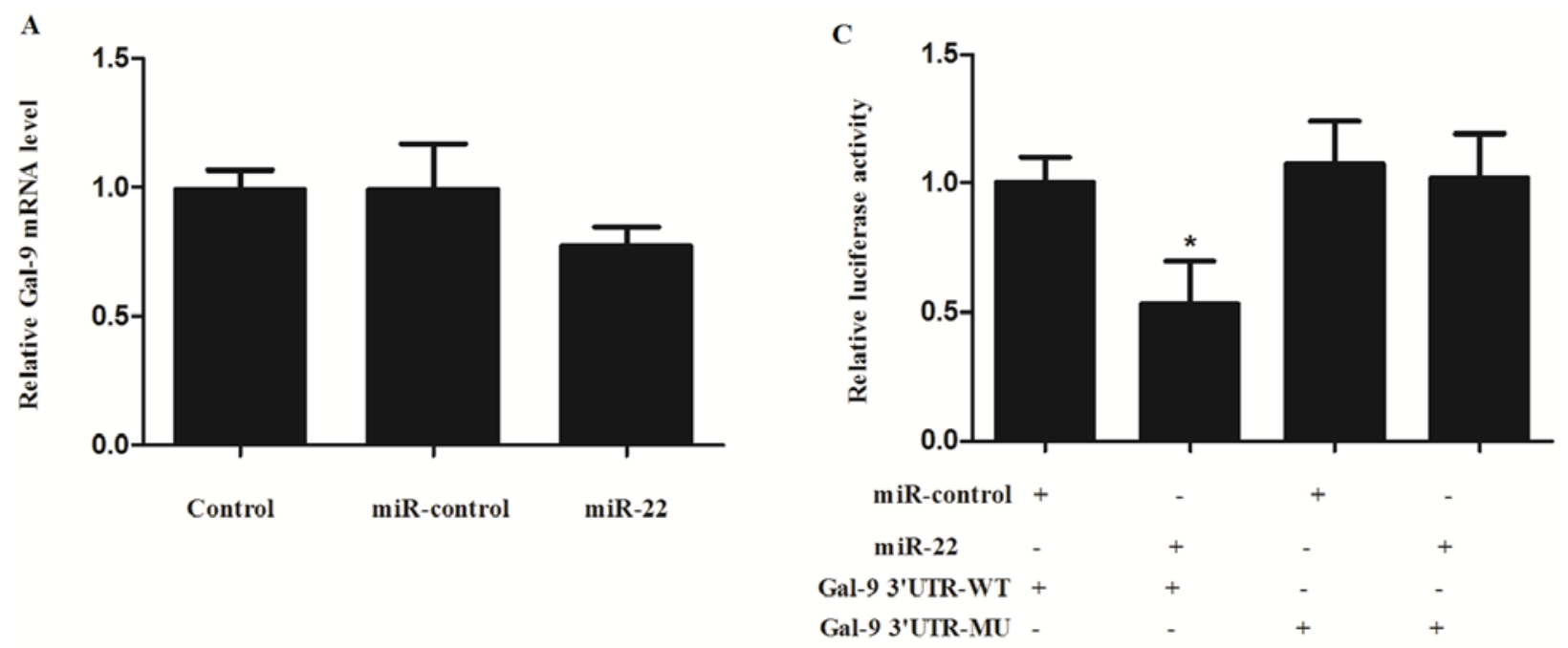

B

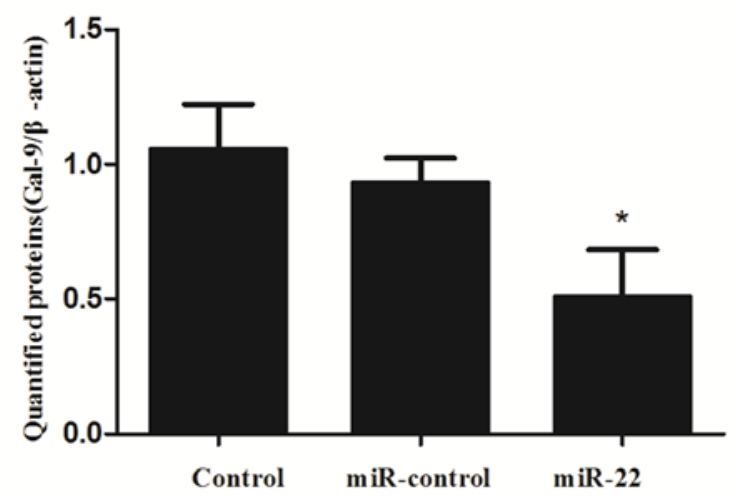

Figure 3. Gal-9 expression was directly inhibited by miR-22. (A) The expression level of Gal-9 mRNA in the HepG2 cells after transfection with the miRcontrol and miR-22 mimics. (B) The expression level of Gal-9 protein in the HepG2 cells after transfection with the miR-control and miR-22 mimics. " $\mathrm{P}=0.04$. (C) The relative luciferase activity following co-transfection of Gal-9 3'UTR-WT or Gal-9 3'UTR-WT and miR-control or miR-22 mimics. The pRL-TK vector was co-transfected as an internal control. ${ }^{*} \mathrm{P}=0.0268$.

or miR-22 mimic, respectively. The luciferase activity was measured after a 24-h transfection. The luciferase activity in the Gal-9 3'UTR-WT group, but not in the Gal-9 3'UTR-MU, was significantly reduced in the cells co-transfected with the miR-22 mimic when compared with the miR-control ( $\mathrm{P}=0.0268$, Fig. 3C).

Influence of the miR-22/Gal-9 axis on tumor cell proliferation and lymphocyte apoptosis. To determine whether the miR-22/Gal-9 axis affects lymphocyte and tumor cell apoptosis, HepG2 cells were divided into four groups: negative control, cells transfected with Gal-9 overexpression vector only, cells transfected with the miR-22 mimics only and cells co-transfected with the Gal-9 overexpression vector and miR-22 mimics. After a $24-\mathrm{h}$ transfection, the liver cancer cells were co-cultured with PBMCs for $48 \mathrm{~h}$ and the apoptosis of PBMCs was detected. Our results showed that the apoptosis rate of the PBMCs co-cultured with the HepG2 cells transfected with the Gal-9 overexpression vector was higher than that of the negative control. The apoptosis rate of the PBMCs co-cultured with the HepG2 cells co-transfected with miR-22 mimics and the Gal-9 overexpression vector was lower than that of the cells transfected with Gal-9 only (Fig. 4A).
In order to further examine the role of the miR-22/Gal-9 axis in tumor cell proliferation, a WST-1 assay was used. The results showed that HepG2 cells transfected with the Gal-9 overexpression vector exhibited higher proliferation compared with the negative control. However, HepG2 cells transfected with the miR-22 mimics only exhibited slower proliferation when compared with the negative control. While HepG2 cells co-transfected with the miR-22 mimics and the Gal-9 overexpression vector showed no significantly different cell proliferation compared to the negative control (Fig. 4B).

\section{Discussion}

The interaction between tumor cells and the tumor microenvironment contributes to the development and progression of cancers (19). In the liver cancer microenvironment, accompanied by extensive lymphocyte infiltration, there is also a large amount of inhibitory factors, which cause the effector $\mathrm{T}$ cells to dysfunction and finally leading to immune escape of hepatic carcinoma cells $(5,20,21)$. Tim-3, an important inhibitory receptor, plays an important role in these processes $(22,23)$.

Gal-9 is one of the specific ligands of Tim- 3 and has been found extracellularly as well as intracellularly, both in the nucleus and in the cytoplasm $(8,24)$. Gal-9 expression is 

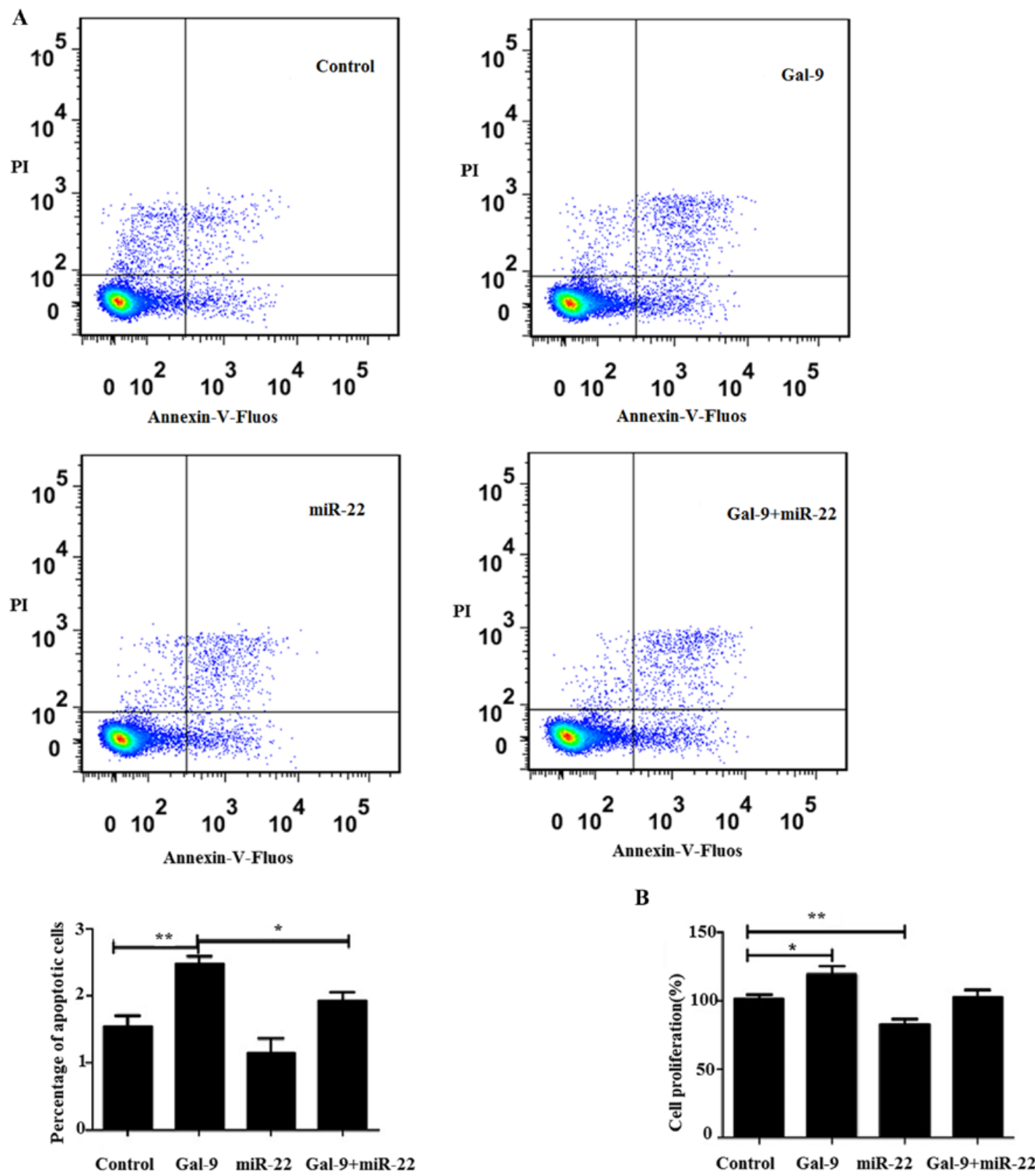

Figure 4. Influence of the miR-22/Gal-9 axis on tumor cell proliferation and lymphocyte cell apoptosis. (A) After transfection and co-culture, the lymphocyte cell apoptosis rate was altered. ${ }^{* *} \mathrm{P}=0.0092$ and ${ }^{*} \mathrm{P}=0.0284$. (B) After transfection and co-culture, the proliferation of HepG2 cell was altered. ${ }^{*} \mathrm{P}=0.0339$ and ${ }^{* *} \mathrm{P}=0.0077$.

widely distributed in tissues involved in the immune system, such as the spleen, thymus and peripheral blood lymphocytes, and in tissues of endodermal origin, such as the liver, intestine, stomach and lung $(25,26)$. Until recently several studies have shown that expression of Gal-9 varies in tumor cells when compared with their normal counterparts. For example, breast, lung and melanoma cancer cell lines showed low or absent Gal-9 expression $(27,28)$, while leukemia and colon cancer cell lines showed high expression of Gal-9 (29). However, little research has been performed to study Gal-9 expression in liver cancer and normal liver cells. In the present study, we first determined the expression of Gal-9 in human hepatocellular carcinoma cell lines (HepG2 and SMMC7721) and in a normal hepatocyte cell line (Lo2). The results showed that HepG2,
SMMC7721 and Lo2 all expressed Gal-9 and Gal-9 was also found to have high expression in human liver cancer cell lines.

In recent years, an important role has been discovered for Gal-9 in health and disease (7). Subsequent studies have revealed that $\mathrm{Gal}-9$ modulates a variety of biological functions, such as cell aggregation and adhesion, apoptosis of tumor cells and others $(8,30)$. The interaction between Gal-9 and Tim-3 expressed on Th1 cells negatively regulates Th1-mediated immune responses $(31,32)$. Furthermore, some studies have revealed that Gal-9 is implicated in the immune escape of tumors through the induction of tumor-specific Tim $3^{+}$T-cell death (33). In the present study, we investigated the effect of Gal-9 on lymphocyte apoptosis and tumor cell proliferation when they were co-cultured in liver cancer cells. Our results 
showed that the apoptosis rate of PBMCs co-cultured with HepG2 cells transfected with the Gal-9 overexpression vector was higher than that of the negative control, while HepG2 cells transfected with the Gal-9 overexpression vector only exhibited higher proliferation compared with the negative control. These results suggest that in liver cancer, the binding of Gal-9 to Tim3 may induce lymphocyte apoptosis and tumor cell immune escape.

To investigate whether the expression of $\mathrm{Gal}-9$ is regulated by miRNAs, we predicted four miRNAs (miR-22,296-3p, 455-5p and 491-5p) as candidate regulators of Gal-9 and examined their expression levels. miR-22 was significantly downregulated in both liver cancer cells and tissues. miR-22, originally identified in HeLa cells, is a type of highly evolutionarily conserved miRNA. Recent studies have shown that miR-22 is an important regulator of cancer oncogenesis and tumor behavior. Previous literature has reported that miR-22 is overexpressed in prostate cancer, but is downregulated in breast cancer, cholangiocarcinoma, multiple myeloma, and HCC (34). Our results showed that miR-22 was significantly downregulated in both liver cancer cells and tissues, consistent with previous results. Luciferase reporter gene assay and detection of Gal-9 mRNA and protein expression after transfection with the miR-22-mimics confirmed that miR-22 directly targets Gal-9 and inhibits the expression of Gal-9 via binding to the specific target site in the Gal-9 3'UTR.

We also observed the effect of the miR-22/Gal-9 axis on lymphocyte exhaustion and apoptosis, as well as tumor cell proliferation and immune evasion. The results showed that the apoptosis rate of PBMCs co-culture with HepG2 cells co-transfected with the miR-22 mimics and the Gal-9 overexpression vector was lower than that of the cells transfected with Gal-9 only, while HepG2 cells transfected with the miR-22 mimics only exhibited slower proliferation when compared with the negative control and HepG2 cells co-transfected with the miR-22 mimics and Gal-9 overexpression vector showed no significant difference in cell proliferation compared to the negative control. The explanation of these phenomena are as follows. Following transfection with miR-22, the expression level of Gal-9 is decreased, disrupting the interaction between Tim-3 and Gal-9 and preventing lymphocytes from apoptosis and partly recovering effector $\mathrm{T}$-cell function and tempering tumor immune response, reducing tumor cell proliferation and immune escape. It may be a novel immune therapeutic target for treating patients with liver cancer

In the present study, we revealed that miR-22 suppresses the expression of Gal-9 and influences T cell function and liver cancer cell immune evasion by affecting the Tim3/Gal-9 pathway. These results would be helpful to investigate the molecular mechanisms underlying liver cancer development from a new perspective and identify novel therapeutic targets for the prevention and treatment of liver cancer.

\section{References}

1. Yi X, Luk JM, Lee NP, Peng J, Leng X, Guan XY, Lau GK, Beretta L and Fan ST: Association of mortalin (HSPA9) with liver cancer metastasis and prediction for early tumor recurrence. Mol Cell Proteomics 7: 315-325, 2008.

2. Siegel R, Naishadham D and Jemal A: Cancer statistics, 2012. CA Cancer J Clin 62: 10-29, 2012.
3. Farazi PA and DePinho RA: Hepatocellular carcinoma pathogenesis: From genes to environment. Nat Rev Cancer 6: 674-687, 2006.

4. Uchino K, Tateishi R, Shiina S, Kanda M, Masuzaki R, Kondo Y, Goto T, Omata M, Yoshida H and Koike K: Hepatocellular carcinoma with extrahepatic metastasis: Clinical features and prognostic factors. Cancer 117: 4475-4483, 2011.

5. Nagahara K, Arikawa T, Oomizu S, Kontani K, Nobumoto A Tateno H, Watanabe K, Niki T, Katoh S, Miyake M, et al: Galectin- 9 increases Tim- $3^{+}$dendritic cells and $C D 8^{+} \mathrm{T}$ cells and enhances antitumor immunity via galectin-9-Tim-3 interactions. J Immunol 181: 7660-7669, 2008.

6. Fujihara S, Mori H, Kobara H, Rafiq K, Niki T, Hirashima M and Masaki T: Galectin-9 in cancer therapy. Recent Pat Endocr Metab Immune Drug Discov 7: 130-137, 2013.

7. Wiersma VR, de Bruyn M, Helfrich W and Bremer E: Therapeutic potential of Galectin-9 in human disease. Med Res Rev 33 (Suppl 1): E102-E126, 2013.

8. Hirashima M, Kashio Y, Nishi N, Yamauchi A, Imaizumi TA, Kageshita T, Saita N and Nakamura T: Galectin-9 in physiological and pathological conditions. Glycoconj J 19: 593-600, 2004.

9. Wang F, He W, Zhou H, Yuan J, Wu K, Xu L and Chen ZK: The Tim-3 ligand galectin-9 negatively regulates $\mathrm{CD} 8^{+}$alloreactive $\mathrm{T}$ cell and prolongs survival of skin graft. Cell Immunol 250: 68-74, 2007.

10. Freeman GJ, Casasnovas JM, Umetsu DT and DeKruyff RH: TIM genes: A family of cell surface phosphatidylserine receptors that regulate innate and adaptive immunity. Immunol Rev 235: $172-189,2010$.

11. Sharma S, Sundararajan A, Suryawanshi A, Kumar N, Veiga-Parga T, Kuchroo VK, Thomas PG, Sangster MY and Rouse BT: T cell immunoglobulin and mucin protein-3 (Tim-3)/Galectin-9 interaction regulates influenza A virusspecific humoral and CD8 T-cell responses. Proc Natl Acad Sci USA 108: 19001-19006, 2011.

12. Heusschen R, Griffioen AW and Thijssen VL: Galectin-9 in tumor biology: A jack of multiple trades. Biochim Biophys Acta 1836: 177-185, 2013.

13. Ambros V: The functions of animal microRNAs. Nature 431: 350-355, 2004

14. Kloosterman WP and Plasterk RH: The diverse functions of microRNAs in animal development and disease. Dev Cell 11: 441-450, 2006.

15. Bartel DP: MicroRNAs: Target recognition and regulatory functions. Cell 136: 215-233, 2009.

16. Bartel DP: MicroRNAs: Genomics, biogenesis, mechanism, and function. Cell 116: 281-297, 2004.

17. Garzon R, Marcucci G and Croce CM: Targeting microRNAs in cancer: Rationale, strategies and challenges. Nat Rev Drug Discov 9: 775-789, 2010.

18. Xiong Y, Fang JH, Yun JP, Yang J, Zhang Y, Jia WH and Zhuang SM: Effects of microRNA-29 on apoptosis, tumorigenicity, and prognosis of hepatocellular carcinoma. Hepatology 51: 836-845, 2010.

19. Cosse JP and Michiels C: Tumour hypoxia affects the responsiveness of cancer cells to chemotherapy and promotes cancer progression. Anticancer Agents Med Chem 8: 790-797, 2008.

20. Fourcade J, Sun Z, Benallaoua M, Guillaume P, Luescher IF, Sander C, Kirkwood JM, Kuchroo V and Zarour HM: Upregulation of Tim-3 and PD-1 expression is associated with tumor antigen-specific $\mathrm{CD} 8^{+} \mathrm{T}$ cell dysfunction in melanoma patients. J Exp Med 207: 2175-2186, 2010.

21. Fourcade J, Kudela P, Sun Z, Shen H, Land SR, Lenzner D, Guillaume P, Luescher IF, Sander C, Ferrone S, et al: PD-1 is a regulator of NY-ESO-1-specific $\mathrm{CD}^{+} \mathrm{T}$ cell expansion in melanoma patients. J Immunol 182: 5240-5249, 2009.

22. Hastings WD, Anderson DE, Kassam N, Koguchi K, Greenfield EA, Kent SC, Zheng XX, Strom TB, Hafler DA and Kuchroo VK: TIM-3 is expressed on activated human CD4 ${ }^{+}$ T cells and regulates Th1 and Th17 cytokines. Eur J Immunol 39: 2492-2501, 2009.

23. Kikushige Y, Shima T, Takayanagi S, Urata S, Miyamoto T, Iwasaki H, Takenaka K, Teshima T, Tanaka T, Inagaki Y, et al: TIM-3 is a promising target to selectively kill acute myeloid leukemia stem cells. Cell Stem Cell 7: 708-717, 2010.

24. Thijssen VL, Hulsmans S and Griffioen AW: The galectin profile of the endothelium: Altered expression and localization in activated and tumor endothelial cells. Am J Pathol 172: 545-553, 2008. 
25. Türeci O, Schmitt H, Fadle N, Pfreundschuh M and Sahin U: Molecular definition of a novel human galectin which is immunogenic in patients with Hodgkin's disease. J Biol Chem 272: 6416-6422, 1997.

26. Wada J, Ota K, Kumar A, Wallner EI and Kanwar YS: Developmental regulation, expression, and apoptotic potential of galectin-9, a beta-galactoside binding lectin. J Clin Invest 99: 2452-2461, 1997.

27. Irie A, Yamauchi A, Kontani K, Kihara M, Liu D, Shirato Y, Seki M, Nishi N, Nakamura T, Yokomise H, et al: Galectin-9 as a prognostic factor with antimetastatic potential in breast cancer. Clin Cancer Res 11: 2962-2968, 2005.

28. Kageshita T, Kashio Y, Yamauchi A, Seki M, Abedin MJ, Nishi N, Shoji H, Nakamura T, Ono T and Hirashima M: Possible role of galectin-9 in cell aggregation and apoptosis of human melanoma cell lines and its clinical significance. Int J Cancer 99: 809-816, 2002.

29. Lahm H, André S, Hoeflich A, Fischer JR, Sordat B, Kaltner H, Wolf $\mathrm{E}$ and Gabius HJ: Comprehensive galectin fingerprinting in a panel of 61 human tumor cell lines by RT-PCR and its implications for diagnostic and therapeutic procedures. J Cancer Res Clin Oncol 127: 375-386, 2001.
30. Asakura H, Kashio Y, Nakamura K, Seki M, Dai S, Shirato Y, Abedin MJ, Yoshida N, Nishi N, Imaizumi T, et al: Selective eosinophil adhesion to fibroblast via IFN-gamma-induced galectin-9. J Immunol 169: 5912-5918, 2002.

31. Zhu C, Anderson AC, Schubart A, Xiong H, Imitola J, Khoury SJ, Zheng XX, Strom TB and Kuchroo VK: The Tim-3 ligand galectin-9 negatively regulates $\mathrm{T}$ helper type 1 immunity. Nat Immunol 6: 1245-1252, 2005.

32. Sánchez-Fueyo A, Tian J, Picarella D, Domenig C, Zheng XX, Sabatos CA, Manlongat N, Bender O, Kamradt T, Kuchroo VK, et al: Tim-3 inhibits T helper type 1-mediated auto- and alloimmune responses and promotes immunological tolerance. Nat Immunol 4: 1093-1101, 2003.

33. Li H, Wu K, Tao K, Chen L, Zheng Q, Lu X, Liu J, Shi L, Liu C, Wang G, et al: Tim-3/galectin-9 signaling pathway mediates T-cell dysfunction and predicts poor prognosis in patients with hepatitis B virus-associated hepatocellular carcinoma. Hepatology 56: 1342-1351, 2012.

34. Zhang J, Yang Y, Yang T, Liu Y, Li A, Fu S, Wu M, Pan Z and Zhou W: microRNA-22, downregulated in hepatocellular carcinoma and correlated with prognosis, suppresses cell proliferation and tumourigenicity. Br J Cancer 103: 1215-1220, 2010. 